\title{
Research on Permeation Grouting Mechanism Considering Gravity in the Treatment of Mud Inrush Disaster
}

\author{
Jianguo Liu, Xiao Zhang, Mengtian Li*, Xiongdong Lan, Pengshuai Hao \\ Geotechnical and Structural Engineering Research Center, Shandong University, Jinan 250061, Shandong, China
}

Received: 20 February 2020

Accepted: 12 June 2020

\begin{abstract}
Mud inrush disaster is a typical geological disaster during the construction of mountain tunnels, which may bring immense economic losses and is very harmful to the local environment. Permeation grouting is an important treatment method for mud inrush disaster, which has been wildly used in China. In this paper, a theoretical model of permeation diffusion of Bingham fluid considering gravity is presented. A set of visual permeation grouting experiment device was designed. The test results verify the new permeation diffusion model showing that the slurry is spherical diffusion, while the strip-shaped diffusion appears under the spherical diffusion. With the increase of grouting quantity, the spherical diffusion radius increases gradually. Meanwhile, both the number and radius of the stripshaped diffusion increases gradually. The regression analysis of grouting quantity of 30 typical test data shows that the degree of influence of the grouting quantity from big to small is: grouting pressure, permeability coefficient, and water-cement ratio. The statistics of the total grouting quantity and the grouting quantity of spherical diffusion indicate that the grouting quantity of strip-shaped diffusion accounted for about $50 \%$, which shows the importance of strip-shaped diffusion in surrounding rock reinforcement. This new diffusion model has certain guiding significance for practice.
\end{abstract}

Keywords: permeation grouting, sand medium, gravity, diffusion mechanism, model experiment

\section{Introduction}

Nowadays, large numbers of mountain tunnels are being constructed in the southwest of China, because of the major national strategies such as the Western Development and One Belt One Road Strategy. In these areas, the engineering geological conditions

*e-mail: mengtian@sdu.edu.cn are very complex, such as fault fractures and karst areas. This will likely lead to mud inrush disaster [1]. The mud inrush disaster will form a large number of loose deposited mass in the tunnel, seriously block the tunnel and bury engineering equipment. It may cause unrecoverable environmental destruction as well [2, 3]. The permeation grouting method can fill the loose deposited mass well and improve the overall strength of the surrounding rock in the tunnel efficiently, which has been widely used in the treatment of mud inrush disaster [4-7]. 
Scholars have studied the mechanism of permeation grouting in many aspects. As early as 1938, Maag's spherical diffusion theory, Raffle's spherical diffusion formula, and cylindrical diffusion formula were classical diffusion theories [8-10]. Huang [11] studied the permeation grouting of saturated sand layer under the action of capillary force. Sun [12] used the calculated finite element model of permeation grout to carry out numerical simulation of diffusion and pressure distribution. Xiao [13] and Zhang [14] studied the infiltration and grouting diffusion mechanism of fast setting slurry, considering the time-space change of slurry viscosity. Many scholars studied the theory of cylindrical-hemispherical penetration grouting of Newtonian fluid. Celik [15] respectively studied the mechanism of cylindrical-hemispherical penetration grouting of Newtonian and Bingham fluid slurry, and provided the theoretical calculation formula of slurry diffusion. Saada [16,17] studied the filtration effect of one-dimensional grouting diffusion and carried out experiments, Then Maghous [18] applied this model to columnar infiltration grouting.

However, all the above theoretical researches on permeation diffusion ignore the influence of gravity, and the shape of grout is generally spherical or cylindrical. In practical engineering applications, gravity cannot be ignored, especially in the process of low-pressure permeation grouting. The shape of slurry is far from spherical and cylindrical. It is often found that less grout remains in the reinforcement area, and the strength cannot meet the expected requirements, using these theoretical models.

In order to retain as much slurry as possible in the target reinforcement area, avoid the ineffective diffusion of grout and analyze the effect of gravity on grout diffusion, the theoretical model of permeation diffusion of point source grouting considering gravity is established. A visible experiment model with a quantitative rotary piston grouting pump capable of low pressure and controllable flow rate is designed, and glass sand and quartz sand is used as the medium of permeation grouting experiment. The theoretical model of grout diffusion is verified in this experiment.

\section{Material and Methods}

\section{Grouting Mechanism Considering Gravity}

The assumptions of the permeation grouting model are as follows:

1) The filling medium is a sand medium with similar particle size and uniform distribution under a certain gradation. The pores of the medium are fully filled with water, and the infiltration effect is not considered in the grouting process.

2) The grout and water are isotropic, homogeneous and incompressible fluids.

3) In permeation grouting, the grouting pressure of this grouting method is very low. Under the condition of low grouting pressure, the initial yield stress of grout can not be negligible. So the grout is considered as Bingham fluid, which is more suitable for actual grout [19].

The pore of the sandy medium can be equivalent to fine pipes in a uniform distribution, and the permeation movement of grout in the medium is equivalent to the flow in the fine pipe [20]. In the process of point-source grouting, the fine pipe starts from the grouting hole and diverges in all directions. As shown in Fig. 1, there is a fine pipe, and the radius is $r_{1}$. Take a section of the fluid column and the mass is $m$, the length is $\mathrm{d} l$, the radius is $r$ which is less than $r_{1}$. So $m=\rho \pi r^{2} \mathrm{~d} l$.

In Fig. $1, p$ is the grout pressure. $\tau$ is the shear stress of the fluid column. The density of grout is $\rho$. $\theta$ is the angle between gravity and the direction of the flow. The force equation considering gravity can be expressed as

$$
p \pi r^{2}-(p+\mathrm{d} p) \pi r^{2}-2 \pi r \tau \mathrm{d} l+\rho g \pi r^{2} \mathrm{~d} l \cos \theta=0
$$

...where $g$ is the gravitational acceleration.

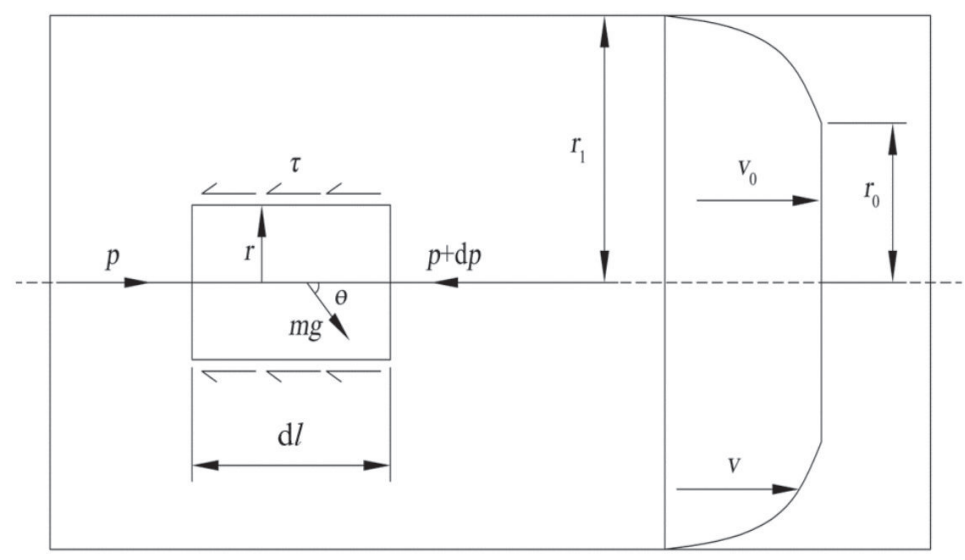

Fig. 1. Force analysis of the fluid column. 
By simplifying the Eq. (1), we can get

$$
\tau=-\frac{r}{2}\left(\frac{\mathrm{d} p}{\mathrm{~d} l}-\rho g \cos \theta\right)
$$

The constitutive equation of Bingham fluid is

$$
\begin{aligned}
& \tau=\tau_{0}+\mu \gamma \\
& \gamma=-d v / d r
\end{aligned}
$$

...where $\tau_{0}$ is the initial yield shear stress and $\mu$ is the initial viscosity.

Combining Eq. (2) and Eq. (3) leads to

$$
\gamma=-\frac{d v}{d r}=\frac{1}{\mu}\left[\frac{r}{2}\left(\cos \theta \rho g-\frac{\mathrm{d} p}{\mathrm{~d} l}\right)-\tau_{0}\right]
$$

For the Bingham fluid, because of the initial yield shear stress, there exists a flow core with a radius of $r_{0}$. when $0 \leq r \leq r_{0}$, the fluid velocity is the same as $v_{0}$, there is no relative motion in this area, when $r_{0} \leq r \leq r_{1}$, the fluid velocity is different.

By integrating Eq. (4), we can get

$$
v=\frac{1}{\mu}\left[\frac{r^{2}}{4}\left(\frac{\mathrm{d} p}{\mathrm{~d} l}-\cos \theta \rho g\right)+\tau_{0} r\right]+C_{1}
$$

...where $C_{1}$ is the integral coefficient.

When $0 \leq r \leq r_{0}$, the fluid velocity $v=v_{0}$, and the velocity equation is

$$
v=v_{0}=\frac{1}{\mu}\left[\left(\frac{\mathrm{d} p}{\mathrm{~d} l}-\cos \theta \rho g\right) \frac{\left(r_{0}^{2}-r_{1}^{2}\right)}{4}+\tau_{0}\left(r_{0}-r_{1}\right)\right]
$$

When $r_{0} \leq r \leq r_{1}$, and at the boundary $r=r_{1}, v=0$, the velocity equation is

$$
v=\frac{1}{\mu}\left[\left(\frac{\mathrm{d} p}{\mathrm{~d} l}-\cos \theta \rho g\right) \frac{\left(r^{2}-r_{1}^{2}\right)}{4}+\tau_{0}\left(r-r_{1}\right)\right]
$$

The grout quantity per unit time can be obtained

$$
q=\int_{r_{0}}^{r_{1}} 2 \pi r v \mathrm{~d} r+\pi r_{0}^{2} v_{0}
$$

And the average velocity is as follows

$$
\begin{gathered}
\bar{v}=\frac{q}{\pi r_{1}^{2}}=\frac{r_{1}^{2}}{8 \mu}\left(\cos \theta \rho g-\frac{\mathrm{d} p}{\mathrm{~d} l}\right)\left[1-\frac{4}{3}\left(\frac{2 \tau_{0} / r_{0}}{\cos \theta \rho g-\mathrm{d} p / \mathrm{d} l}\right)\right. \\
\left.+\frac{1}{3}\left(\left(\frac{2 \tau_{0} / r_{0}}{\cos \theta \rho g-\mathrm{d} p / \mathrm{d} l}\right)^{4}\right)\right]
\end{gathered}
$$

In the sandy soil, the relationship between fluid velocity and average velocity is as follows:

$$
V=n \bar{v}
$$

...where $\mathrm{V}$ is fluid velocity and $n$ is the porosity of porous media.

Here, introducing variable $\mathrm{K}$

$$
K=\frac{n r_{1}^{2}}{8}
$$

Introducing Eq. (10) and Eq. (11) into Eq. (9) leads to

$$
\begin{gathered}
V=\frac{K}{\mu}\left(\cos \theta \rho g-\frac{\mathrm{d} p}{\mathrm{~d} l}\right)\left[1-\frac{4}{3}\left(\frac{2 \tau_{0} / r_{0}}{\cos \theta \rho g-\mathrm{d} p / \mathrm{d} l}\right)\right. \\
\left.+\frac{1}{3}\left(\left(\frac{2 \tau_{0} / r_{0}}{\cos \theta \rho g-\mathrm{d} p / \mathrm{d} l}\right)^{4}\right)\right]
\end{gathered}
$$

At the beginning, fluid does not move in the pipe and $V=0$, it leads to

$$
\frac{2 \tau_{0} / r_{0}}{\cos \theta \rho g-\mathrm{d} p / \mathrm{d} l}=1
$$

Thus, the starting viscosity gradient $\lambda$ can be express as

$$
\lambda=-\frac{\mathrm{d} p}{\mathrm{~d} l}=\frac{2 \tau_{0}}{r_{0}}-\cos \theta \rho g
$$

Introducing $\lambda$ into Eq. (12), it leads to

$$
\begin{gathered}
V=\frac{K}{\mu}\left(\cos \theta \rho g-\frac{\mathrm{d} p}{\mathrm{~d} l}\right)\left[1-\frac{4}{3}\left(\frac{\lambda+\cos \theta \rho g}{\cos \theta \rho g-\mathrm{d} p / \mathrm{d} l}\right)\right. \\
\left.+\frac{1}{3}\left(\left(\frac{\lambda+\cos \theta \rho g}{\cos \theta \rho g-\mathrm{d} p / \mathrm{d} l}\right)^{4}\right)\right]
\end{gathered}
$$

Since $-\mathrm{d} p / \mathrm{d} l$ is much larger than the starting viscosity gradient $\lambda$, the higher order term in the velocity expression is negligible [21]. The expression of the permeation velocity $V$ can be obtained

$$
V=\frac{K}{\mu}\left(\cos \theta \rho g-\frac{\mathrm{d} p}{\mathrm{~d} l}\right)\left[1-\frac{4}{3}\left(\frac{\lambda+\cos \theta \rho g}{\cos \theta \rho g-\mathrm{d} p / \mathrm{d} l}\right)\right]
$$

The classical spherical diffusion theory only considers the spherical diffusion of the grout under the action of grouting pressure, and the actual situation is accompanied by the joint action of gravity and pressure. 
(1) spherical diffusion of Bingham fluid considering gravity

The sandy medium is filled with water, as shown in Fig. 2. $a$ is the radius of the grouting pipe. $p_{1}$ is the grouting pressure in the grouting pipe. $p$ is the grouting pressure.

As shown in Fig. 2, the grouting quantity is approximately equal to

$$
Q=V A t
$$

...where $A$ is total surface area $A=4 \pi l^{2}, t$ is the grouting time.

Combining Eq. (16) and Eq. (17) leads to

$V=\frac{Q}{4 \pi t l^{2}}=\frac{K}{\mu}\left(\cos \theta \rho g-\frac{\mathrm{d} p}{\mathrm{~d} l}\right)\left[1-\frac{4}{3}\left(\frac{\lambda+\cos \theta \rho g}{\cos \theta \rho g-\mathrm{d} p / \mathrm{d} l}\right)\right]$

Separating variables and integrating Eq. (18), it yields

$$
p=\frac{Q \mu}{4 \pi K t l}-\left(\frac{1}{3} \cos \theta \rho g+\frac{4}{3} \lambda\right) l+C_{2}
$$

...where $C_{2}$ is the integral coefficient.

At the grouting hole, the boundary conditions is that $p=p_{1}$ and $l=a$. So $C_{2}$ can be obtained

$$
C_{2}=p_{1}-\frac{Q \mu}{4 \pi K t a}-\left(\frac{1}{3} \cos \theta \rho g+\frac{4}{3} \lambda\right) a
$$

Combining Eq. (19) and Eq. (20) leads to

$p=\frac{Q \mu}{4 \pi K t l}-\left(\frac{1}{3} \cos \theta \rho g+\frac{4}{3} \lambda\right) l+p_{1}-\frac{Q \mu}{4 \pi K t a}-\left(\frac{1}{3} \cos \theta \rho g+\frac{4}{3} \lambda\right) a$
At the end of grouting, the boundary conditions is that the grouting pressure $p$ is equal to water pressure $p_{0}, l=l_{\max }$, where $l_{\max }$ is the maximum diffusion radius.

The grouting quantity $Q$ can be expressed as

$$
Q=\frac{4}{3} \pi l_{\max }^{3} n
$$

...where $n$ is the porosity of porous media.

Together with Eq. (21), Eq. (22) and boundary conditions, it is found that

$$
p_{1}-p_{0}=\frac{n \mu}{3 t K a} l_{\max }^{3}-\frac{n \mu}{3 t K} l_{\max }^{2}-\left(\frac{4}{3} \lambda+\frac{1}{3} \rho g \cos \theta\right)\left(a-l_{\max }\right)
$$

In the Eq. (23), $l_{\max }$ is the only unknown parameter. Given a certain $\theta$, we can get the exact shape of the slurry by solving Eq. (23).

(2) Strip permeation grout vein considering gravity

The above inference is the spherical diffusion of deformation under the action of gravity. It is assumed that the quantity of grouting is $Q_{0}$. If gravity is considered, the grout will diffuse to the area below the grouting hole, and the media pores can be equivalent to the vertical fine pipe. From Eq. (1), the force equation of the grout column in the vertical fine pipe under gravity is:

$$
\pi r^{2} \mathrm{~d} p+2 \pi r \tau \mathrm{d} b-\rho \pi r^{2} g \mathrm{~d} l=0
$$

The grout diffused vertically downward in stripshape with permeation velocity $v^{\prime}$, and the radius of strip-shape is $a$, as shown in Fig. 3(A). Assuming that a certain amount grout of length $h_{1}$ in the grouting pipe is injected into the sandy medium and diffuses into a strip-shape grout vein with the length of $h_{2}$ and the

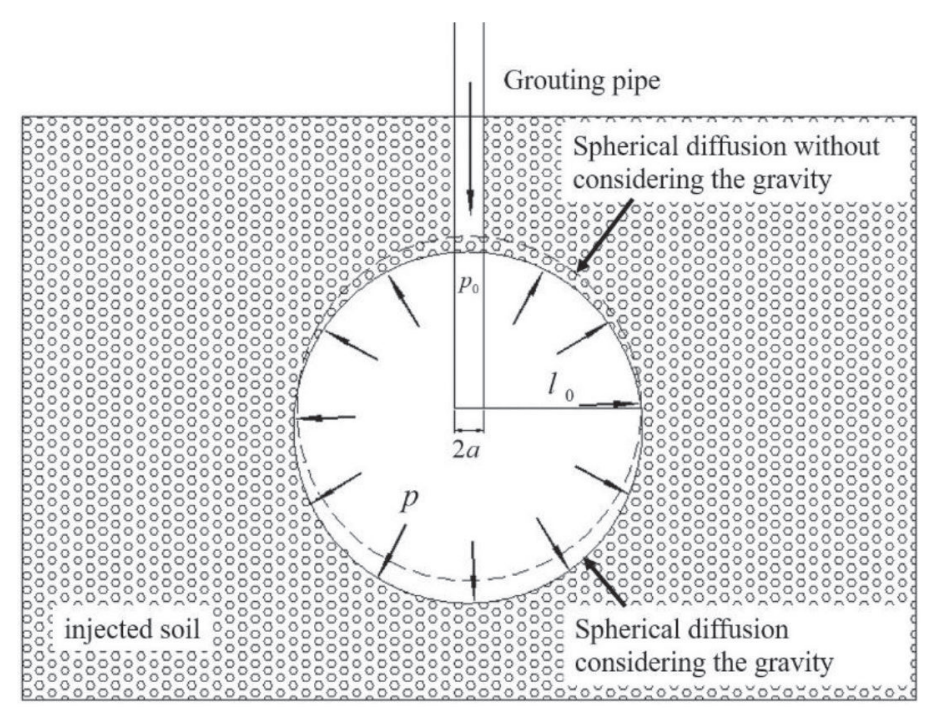

Fig. 2. Spherical diffusion of Bingham fluid. 


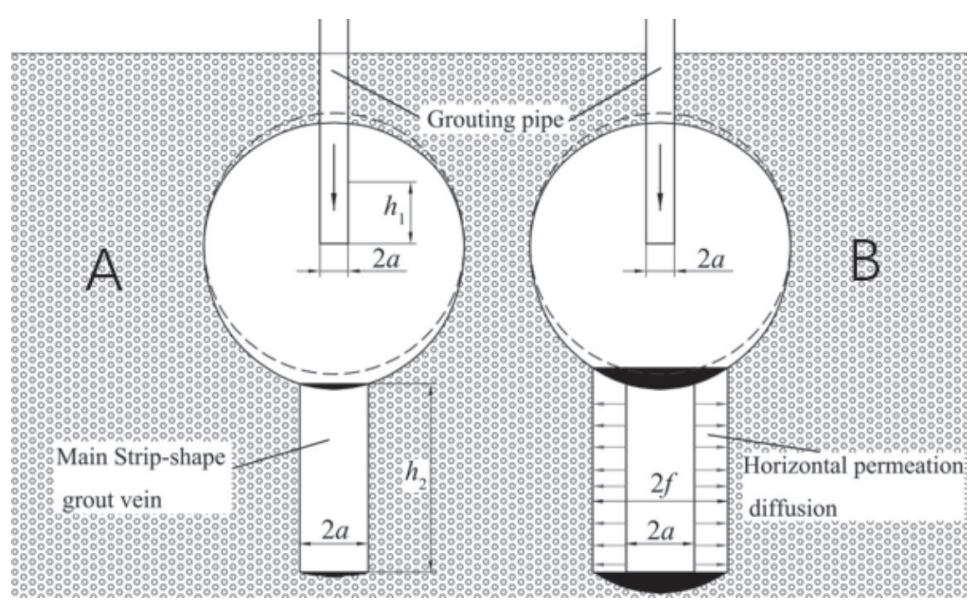

Fig. 3. Vertical and transverse diffusion of main strip.

radius is $a$. The expression of the grouting quantity is:

$$
Q_{\mathrm{a}}^{\prime}=\pi a^{2} v_{2}^{\prime} t n=\pi a^{2} h_{2} n=\pi a^{2} h_{1}
$$

...where $Q_{\mathrm{a}}^{\prime}$ is the quantity of grouting for the vertical permeation of the main strip-shape grout vein. $h_{2}$ is the vertical diffusion distance of the slurry.

At this situation, $\theta=0$, Substituting $\theta=0$ into Eq. (16), it can be found that

$$
v_{2}^{\prime}=\frac{K}{\mu}\left(\rho g-\frac{\mathrm{d} p}{\mathrm{~d} l}\right)\left[1-\frac{4}{3}\left(\frac{\lambda+\rho g}{\rho g-\mathrm{d} p / \mathrm{d} l}\right)\right]
$$

Substituting Eq. (26) into Eq. (25), the vertical permeation grouting quantity of the main grout vein can be obtained as follows:

$$
Q_{\mathrm{a}}^{\prime}=\frac{\pi a^{2} K n t}{\mu}\left(\rho g-\frac{\mathrm{d} p}{\mathrm{~d} l}\right)\left[1-\frac{4}{3}\left(\frac{\lambda+\rho g}{\rho g-\mathrm{d} p / \mathrm{d} l}\right)\right]_{(27)}
$$

The length of vertical permeation grout vein is:

$$
h_{2}=\frac{K t}{\mu}\left(\rho g-\frac{\mathrm{d} p}{\mathrm{~d} l}\right)\left[1-\frac{4}{3}\left(\frac{\lambda+\rho g}{\rho g-\mathrm{d} p / \mathrm{d} l}\right)\right]
$$

The length of consumed grout in the grouting pipe is:

$$
h_{1}=\frac{K t n}{\mu}\left(\rho g-\frac{\mathrm{d} p}{\mathrm{~d} l}\right)\left[1-\frac{4}{3}\left(\frac{\lambda+\rho g}{\rho g-\mathrm{d} p / \mathrm{d} l}\right)\right]
$$

While the kinetic energy and pressure potential energy drive the grout to diffuse vertically downward, the residual pressure in the strip-shaped veins will drive the veins to permeate horizontally to form a cylinder with a radius $f$. The process of gradually thickening of the strip-shaped veins can be similar to the columnar diffusion of the grouting through screen pipe. As shown in Fig. 3(B), the grout quantity required for strip-shaped veins can be expressed as

$$
Q_{0}^{\prime}=\pi f^{2} v_{3}^{\prime} t n=\pi f^{2} h_{2} n
$$

The diffusion radius of the grout in the horizontal direction can ignore the influence of gravity, and the permeation velocity can be referred to Eq. (23). it can be known that the columnar diffusion formula of Bingham fluid is:

$$
\Delta p=p_{1}-p_{0}=\frac{n \mu}{3 t K a} f^{3}-\frac{n \mu}{3 t K} f^{2}-\frac{4}{3} \lambda(a-f)
$$

...where $\Delta p$ is the difference between the internal pressure of the strip-shaped slurry and the surrounding pore water pressure.

In the Eq. (31), $f$ is the only unknown parameter. we can get the radius of main strip-shaped veins by solving Eq. (31).

(3) Total grouting quantity

Due to the irregular shape and different sizes of the sand medium particles, as the grouting time increases, the pressure in the deformed sphere gradually increases. Under the action of gravity, new lateral strip-shape veins will appear randomly in the lower hemisphere of the deformed sphere. The number of lateral stripshape veins will increase gradually, and each vein will gradually thicken. As shown in Fig. 4.

Suppose that the grouting quantity consumed by the spherical diffusion is $Q_{0}$, and the grouting quantity consumed by the main strip-shaped slurry is $Q_{0}^{\prime}$. The number of lateral strip-shaped grout veins is $N$, the grout quantity for each of lateral strip-shaped grout veins is $Q_{\mathrm{i}}^{\prime}$. The total grout quantity is:

$$
Q=Q_{0}+Q_{0}^{\prime}+\sum_{i=1}^{N-1} Q_{i}^{\prime}
$$




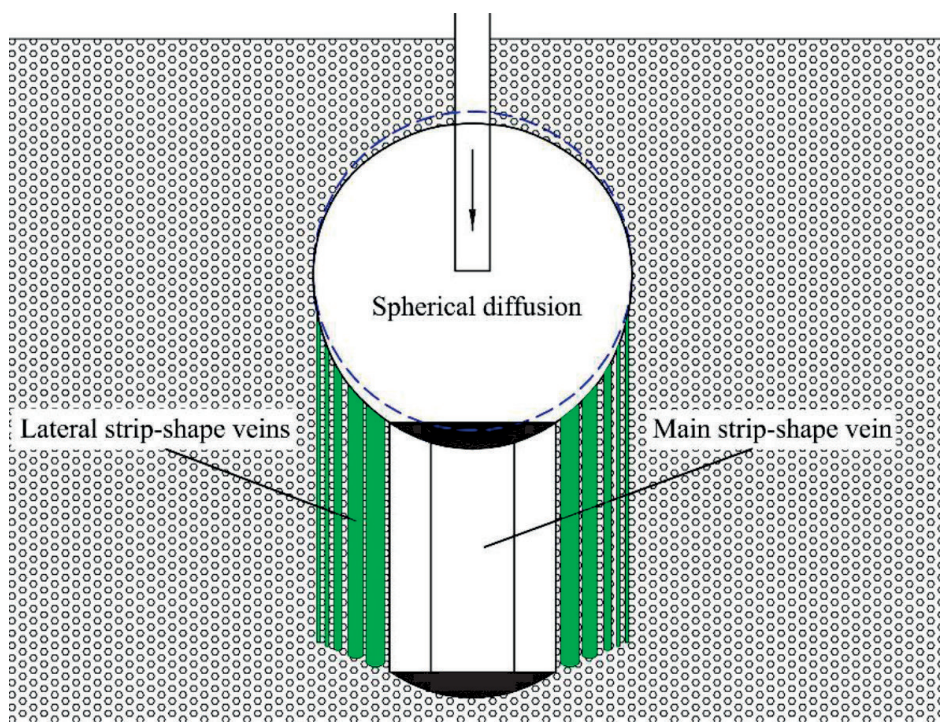

Fig. 4. Diffusion of lateral strip.

\section{Grouting Model Experiment}

In order to verify the theoretical model of Bingham fluid permeation diffusion in sandy media under gravity, a low pressure grouting model experiment was carried out.

\section{Experiment System}

The experimental models are mainly divided into: grout injection system (rotary piston pump, grout barrel and grouting pipeline), parameter acquisition system (pressure sensor, flow sensor and measuring cup), visual grouting system (Plexiglas model barrel and transparent glass san (1) Instruments and materials

- Grouting material: composite polymer cement.

- Injected medium materials: glass sand, standard sand.

- Grouting equipment: rotary piston pump.

- Detection components: pressure sensors, flow sensors, measuring cups.

- Measuring instruments: laser particle size analyzer, sine wave vibrating viscometer, porosity measuring instrument, permeameter.
(2) Experimental method

A three-dimensional vibrating screen was used to screen the glass sand of 1.25-2.5 mm (sample 1), standard sand of 1.25-2.5 mm (sample 2), and standard sand of 0.63-1.25 $\mathrm{mm}$ (sample 3). The medium particles are poured into the Plexiglas model barrel uniformly, and the appropriate quantity of water is poured to make the medium saturated. The grouting pipe is inserted into the sandy medium, $70 \mathrm{~mm}$ below the top. The grouting experiments were carried out in three kinds of porous media samples by using composite polymer cement with different water-cement ratios. The experimental data such as grouting quantity, grouting pressure and grouting time were recorded to study the influence of water-cement ratio, permeability coefficient and grout quantity on grout diffusion. 6 hours after the grouting experiment, the sand is removed and the grout veins are exposed.

(3) Material testing

The polymer additive of the composite cement is polycarboxylate ether-type SP. The property of polycarboxylate ether-type SP is shown in Table 1. This kind of composite cement material has the characteristics of high fluidity and early strength.

Table 1. Property of polycarboxylate ether-type SP in this study.

\begin{tabular}{|c|c|c|c|c|c|c|}
\hline Aspect & Specific gravity & $\mathrm{pH}$ & $\begin{array}{c}\text { Chloride ion } \\
\text { content }\end{array}$ & $\begin{array}{c}\text { Solid content } \\
(\%)\end{array}$ & $\begin{array}{c}\text { Molecular mass } \\
(\mathrm{g} / \mathrm{mol})\end{array}$ & $\begin{array}{c}\text { Recommended } \\
\text { dosage }(\%)\end{array}$ \\
\hline Slightly yellow & 1.05 & $6.3 \pm 0.5$ & Chloride free & 40 & 44000 & $0.6 \sim 1.4$ \\
\hline
\end{tabular}

Table 2. Initial viscosity of composite polymer materials cement paste with different water-cement ratio.

\begin{tabular}{|c|c|c|c|c|c|c|c|}
\hline$m_{\text {water }} / m_{\text {cement }}$ & 0.60 & 0.70 & 0.80 & 1.00 & 1.25 & 1.50 & 2.00 \\
\hline$\eta /(\mathrm{MPa} \cdot \mathrm{s})$ & 24.35 & 13.82 & 10.75 & 6.34 & 4.13 & 3.46 & 2.65 \\
\hline
\end{tabular}


Table 3. Porosity and permeability coefficient of the sample.

\begin{tabular}{|c|c|c|}
\hline Sample & Porosity & Permeability coefficient $(\mathrm{cm} / \mathrm{s})$ \\
\hline 1 & $35.02 \%$ & 0.204 \\
\hline 2 & $40.32 \%$ & 0.132 \\
\hline 3 & $39.30 \%$ & 0.103 \\
\hline
\end{tabular}

It is widely used in China's seepage grouting project, with good effect and representativeness.

The initial viscosity of the cement with different water-cement ratios is measured as shown in Table 2 . It can be found that the initial viscosity of grout gradually decreases with the increase of water-cement ratio. The particle size of composite polymer cement is tested by laser particle size analyzer: $D_{15}=2.040 \mu \mathrm{m}$, $D_{50}=9.610 \mu \mathrm{m}, D_{\text {av }}=12.851 \mu \mathrm{m} . D_{15}$ is the diameter corresponding to $15 \%$ on the particle size distribution curve. $D_{50}$ is the diameter corresponding to $50 \%$ on the particle size distribution curve. $D_{\text {av }}$ is represent an average diameter of granularity.
When the water-cement ratio is less than 1.25 , the cement slurry conforms to the rheological curve of Bingham fluid, so the cement slurry with the watercement ratio of 0.6-1.25 is used in the experiment of Bingham fluid permeation grouting. Porosity $(n)$ and permeability coefficient $(\kappa)$ of the filling medium are tested by porosity meter and permeation meter as shown in Table 3 .

\section{Results and Discussion}

\section{Experimental Phenomenon}

By exposing the grout veins, the diffusion process in the sandy medium includes spherical diffusion and strip-shaped diffusion, and the strip-shaped slurry veins are divided into main strip-shape vein and lateral stripshape veins. With the increasing of grout quantity, the diameter of the spherical diffusion increases gradually. The experimental samples with 1.25-2.5 mm glass sand and the water-cement ratio of 1 are selected for analysis.

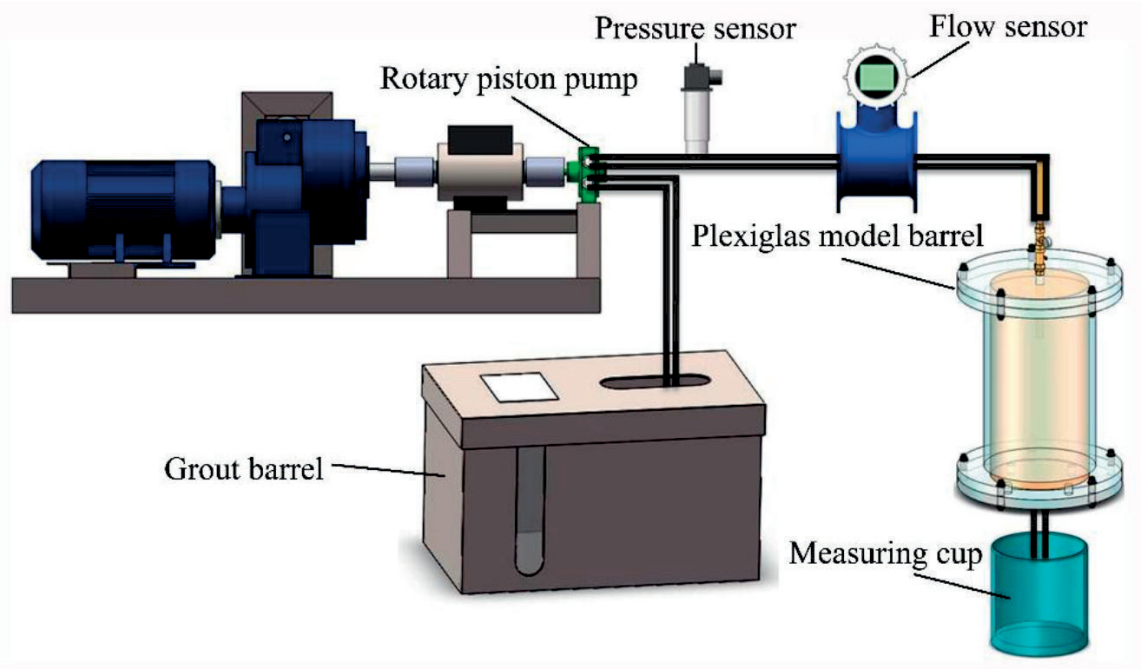

Fig. 5. Experiment system for visual low pressure and slow permeation grouting.

Table 4. Experiment results of permeation grouting considering different grouting quantities.

\begin{tabular}{|c|c|c|c|}
\hline Number & $\begin{array}{c}\text { Grouting Quantity } \\
(\mathrm{ml})\end{array}$ & $\begin{array}{c}\text { Grouting Pressure } \\
(\mathrm{MPa})\end{array}$ & Remark \\
\hline $\mathrm{a}$ & 40 & 0.012 & One $22 \mathrm{~mm}$ main grout vein was found at the lower end of the sphere \\
\hline $\mathrm{b}$ & 80 & 0.011 & Two $20 \mathrm{~mm}$ lateral veins \\
\hline $\mathrm{c}$ & 200 & 0.012 & Three $20 \mathrm{~mm}$ lateral veins with cementation phenomenon \\
\hline $\mathrm{d}$ & 500 & 0.023 & One $25 \mathrm{~mm}$ main grout vein and four $15 \mathrm{~mm}$ lateral veins \\
\hline $\mathrm{e}$ & 700 & 0.039 & One $25 \mathrm{~mm}$ main grout vein and seven $17 \mathrm{~mm}$ lateral veins \\
\hline $\mathrm{f}$ & 1000 & 0.068 & One $30 \mathrm{~mm}$ main grout vein and nine $17 \mathrm{~mm}$ lateral veins \\
\hline $\mathrm{g}$ & 1500 & 0.071 & One $45 \mathrm{~mm}$ main grout vein and thirteen $17 \mathrm{~mm}$ lateral veins \\
\hline $\mathrm{h}$ & 2000 & 0.075 & One $60 \mathrm{~mm}$ main grout vein, and lateral veins were cemented \\
\hline
\end{tabular}




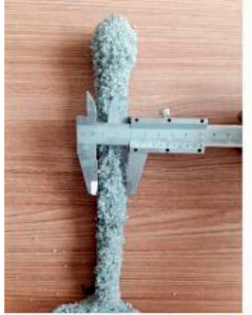

(a) $40 \mathrm{ml}$

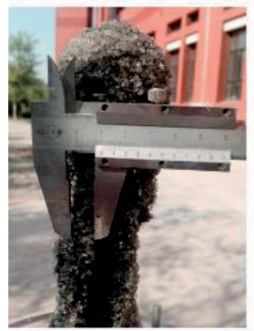

(e) $700 \mathrm{ml}$

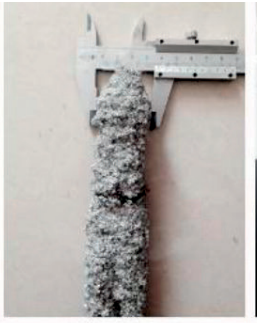

(b) $80 \mathrm{ml}$

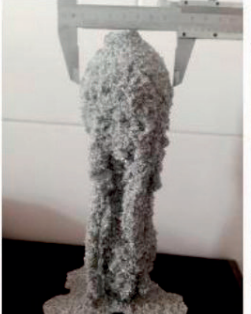

(f) $1000 \mathrm{ml}$

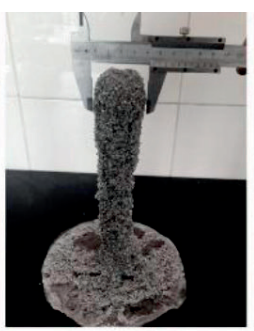

(c) $200 \mathrm{ml}$

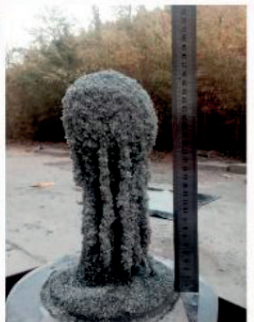

(g) $1500 \mathrm{ml}$

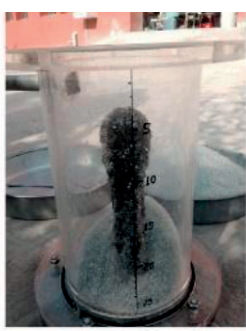

(d) $500 \mathrm{ml}$

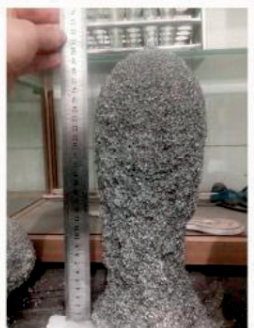

(h) $2000 \mathrm{ml}$

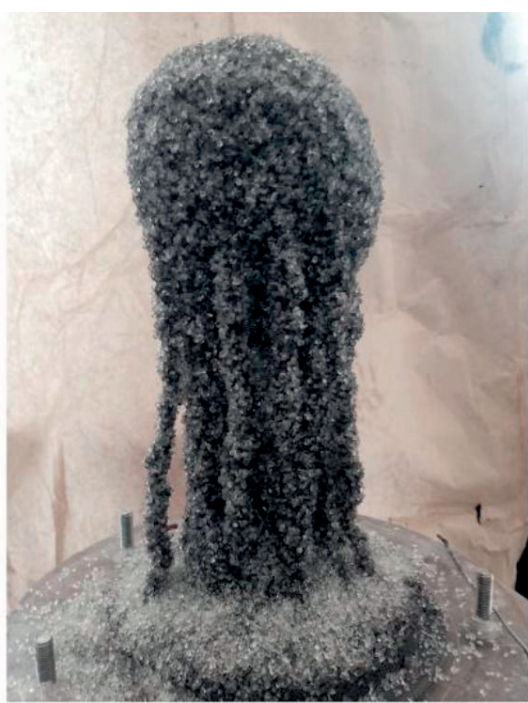

(i) Shape of grout vein at $1500 \mathrm{ml}$

Fig. 6. Grouting effect of different grouting volume.

The experimental records and veins distribution are shown in Table 4 and Fig. 6. $Q$ is the grout quantity and $P$ is the maximum grouting pressure. With the increase of grouting quantity, the main vein thickens, the lateral vein gradually increases, and it is thickened and cemented with the main vein. The most obvious phenomenon appears when the grouting quantity is $1500 \mathrm{ml}$, as shown in Fig. 6i).

Fig. 7 shows the fluctuation curve of grouting pressure in the entire grouting process. With the increase of grouting quantity, the grouting pressure shows an overall upward trend, and accompanied by 13 fluctuations. When the grouting pressure reaches the peak value of $P_{1}-P_{13}$ (13 times), it suddenly decreases. This is because a new strip grout vein is generated When the pressure reaches the peak value, the pressure is released, resulting in a sharp drop in pressure.

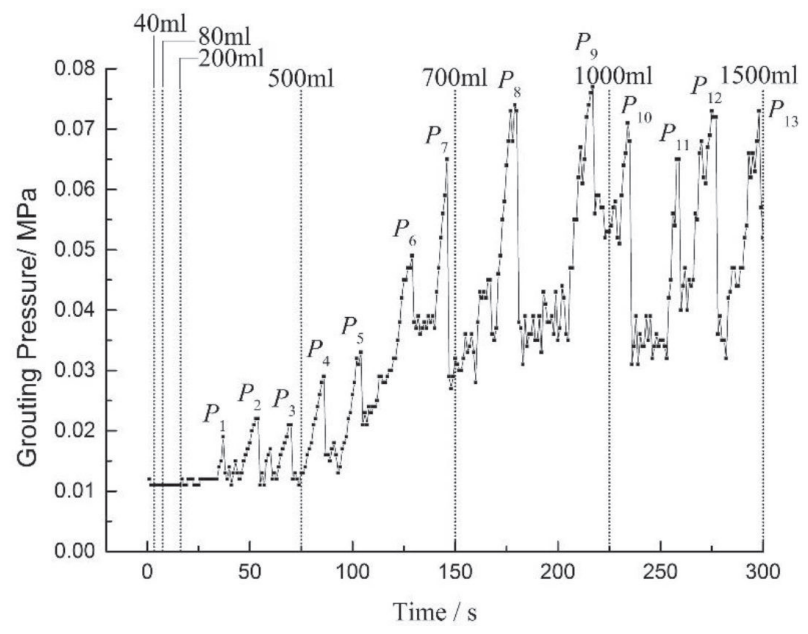

Fig. 7. Process grouting pressure when the grouting volume is $1500 \mathrm{ml}$.

\section{Influence of Water-Cement Ratio on Grout Diffusion}

In sample 1,2 and 3, the maximum grouting pressures and the diameters of diffusion sphere are $P_{1}, P_{2}, P_{3}, D_{1}, D_{2}$, and $D_{3}$. The variation law of $P$ and $D$ with the slurry water-cement ratio is shown in Fig. 8.

It can be seen from Fig. 8 that when the watercement ratio ranges from 0.6 to 1.25 , the required grouting pressure gradually decreases, and the grout spherical diffusion radius gradually increases. As the water-cement ratio increases, the grout viscosity decreases, the required grouting pressure decreases gradually, and the diameter of spherical diffusion zone increases gradually.

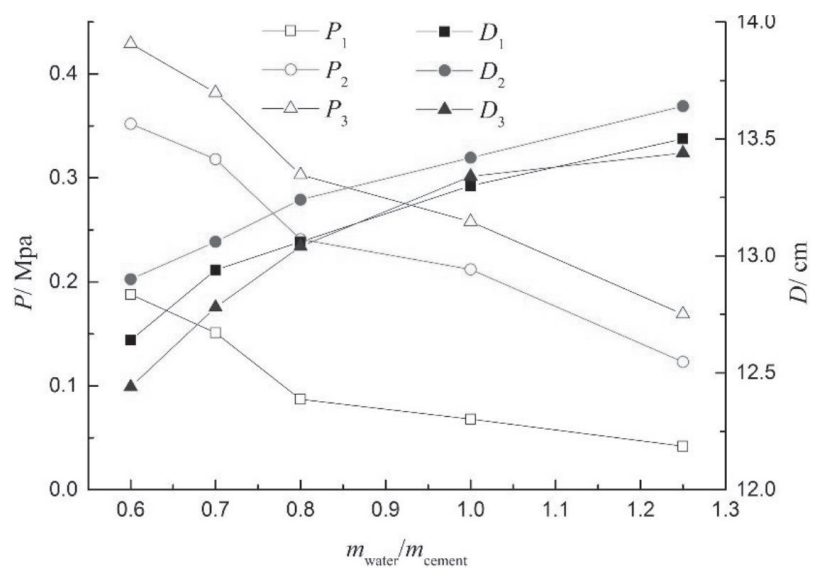

Fig. 8. Variation trend of maximum grouting pressure and the sphere diameter with water cement ratio. 


\section{Regression Analysis of Grouting Quantity}

The quantity of grouting is in a power function relationship with the grouting pressure, the watercement ratio, and the permeability coefficient of the sandy medium. The grouting quantity is in accordance with the model:

$$
Q=E X_{1}{ }^{F} \cdot X_{2}^{G} X_{3}^{H}
$$

The equation is nonlinear. Take the logarithm of both sides of the equation to get:

$$
\lg Q=\lg E+F \lg X_{1}+G \lg X_{2}+H \lg X_{3}
$$

Assume $j=\lg Q, s=\lg E, x_{1}=\lg X_{1}, x_{2}=\lg X_{2} x_{3}=\lg X_{3}$. The equation can be converted into:

$$
j=s+F x_{1}+G x_{2}+H x_{3}
$$

\begin{tabular}{|c|c|c|c|c|c|c|}
\hline Number & $\begin{array}{c}\text { Grouting pressure } \\
X_{1} / \mathrm{MPa}\end{array}$ & $\begin{array}{c}\text { Permeability } \\
\text { coefficient } \\
X_{2} /(\mathrm{cm} / \mathrm{s}) \\
\end{array}$ & $\begin{array}{c}\text { Water-cement } \\
\text { ratio } \\
X_{3} \\
\end{array}$ & $\begin{array}{c}\text { Grouting } \\
\text { quantity } \\
Q /(\mathrm{ml}) \\
\end{array}$ & $\begin{array}{c}\text { Spherical diffusion } \\
\text { radius } \\
L /(\mathrm{mm}) \\
\end{array}$ & $\begin{array}{c}\text { Proportion of } \\
\text { strip-shaped } \\
\text { veins } \\
\end{array}$ \\
\hline 1 & 0.062 & 0.204 & 0.8 & 500 & 54.5 & $47.49 \%$ \\
\hline 2 & 0.069 & 0.204 & 0.8 & 700 & 58.7 & $42.39 \%$ \\
\hline 3 & 0.087 & 0.204 & 0.8 & 1000 & 65.3 & $40.85 \%$ \\
\hline 4 & 0.012 & 0.204 & 1 & 200 & 43.2 & $59.13 \%$ \\
\hline 5 & 0.023 & 0.204 & 1 & 500 & 55.9 & $51.25 \%$ \\
\hline 6 & 0.039 & 0.204 & 1 & 700 & 60.2 & $45.72 \%$ \\
\hline 7 & 0.068 & 0.204 & 1 & 1000 & 66.5 & $43.14 \%$ \\
\hline 8 & 0.012 & 0.204 & 1.25 & 500 & 57.5 & $55.77 \%$ \\
\hline 9 & 0.033 & 0.204 & 1.25 & 700 & 62.2 & $50.43 \%$ \\
\hline 10 & 0.042 & 0.204 & 1.25 & 1000 & 67.5 & $45.11 \%$ \\
\hline 11 & 0.149 & 0.132 & 0.8 & 500 & 53.5 & $44.93 \%$ \\
\hline 12 & 0.189 & 0.132 & 0.8 & 700 & 59.2 & $43.48 \%$ \\
\hline 13 & 0.241 & 0.132 & 0.8 & 1000 & 66.2 & $42.56 \%$ \\
\hline 14 & 0.102 & 0.132 & 1 & 200 & 42.3 & $55.51 \%$ \\
\hline 15 & 0.122 & 0.132 & 1 & 500 & 54.7 & $48.02 \%$ \\
\hline 16 & 0.157 & 0.132 & 1 & 700 & 61.1 & $47.8 \%$ \\
\hline 17 & 0.212 & 0.132 & 1 & 1000 & 67.1 & $44.32 \%$ \\
\hline 18 & 0.088 & 0.132 & 1.25 & 500 & 58.7 & $59.34 \%$ \\
\hline 19 & 0.102 & 0.132 & 1.25 & 700 & 61.8 & $49.46 \%$ \\
\hline 20 & 0.123 & 0.132 & 1.25 & 1000 & 68.2 & $46.53 \%$ \\
\hline 21 & 0.191 & 0.103 & 0.8 & 500 & 54.1 & $46.45 \%$ \\
\hline 22 & 0.256 & 0.103 & 0.8 & 700 & 58.9 & $42.82 \%$ \\
\hline 23 & 0.303 & 0.103 & 0.8 & 1000 & 65.2 & $40.66 \%$ \\
\hline 24 & 0.187 & 0.103 & 1 & 200 & 43.1 & $58.72 \%$ \\
\hline 25 & 0.203 & 0.103 & 1 & 500 & 56.2 & $52.08 \%$ \\
\hline 26 & 0.221 & 0.103 & 1 & 700 & 59.3 & $43.7 \%$ \\
\hline 27 & 0.258 & 0.103 & 1 & 1000 & 66.7 & $43.53 \%$ \\
\hline 28 & 0.124 & 0.103 & 1.25 & 500 & 57.3 & $55.19 \%$ \\
\hline 29 & 0.152 & 0.103 & 1.25 & 700 & 62.3 & $50.67 \%$ \\
\hline 30 & 0.169 & 0.103 & 1.25 & 1000 & 67.2 & $44.52 \%$ \\
\hline
\end{tabular}

Table 5. Experiment parameter record 

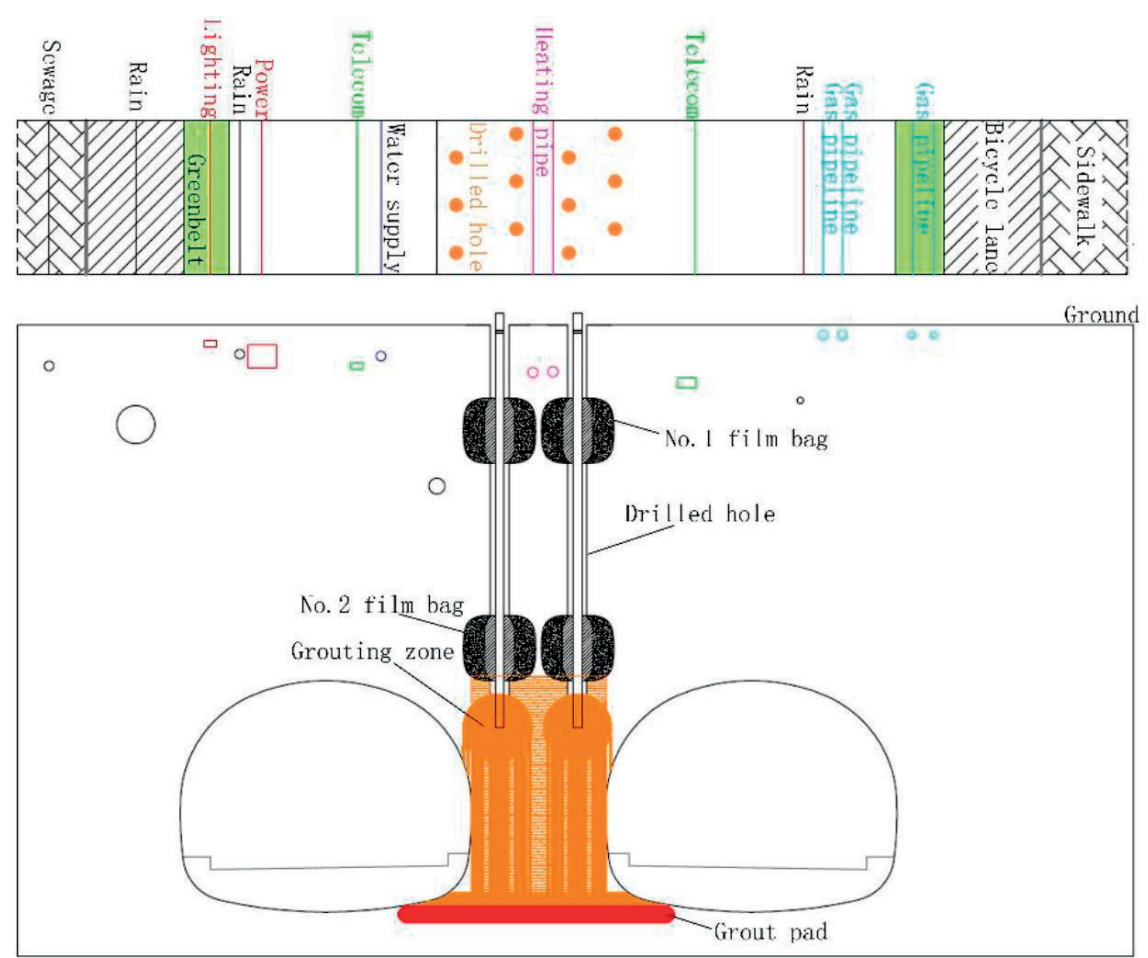

Fig. 9. Middle column grouting project.

...where $Q$ is the total grouting quantity. $E, F, G, H$ are constants. $X_{1}$ is the grouting pressure. $X_{2}$ is the permeability coefficient. $X_{3}$ is the water-cement ratio.

The different grouting pressures, permeability coefficient, water-cement ratio, grouting quantity, and spherical diffusion radius $(L)$ and their percentages in the total grouting quantity in the 30 groups are counted, as shown in Table 5. According to the multiple regression analysis method, using SPSS Statistics for multiple regression analysis, the following conclusions can be drawn: $F$ statistic observation value (7.217) is significantly larger than $\mathrm{F}(3,24)$ (3.009), and the grouting quantity has a significant linear relationship with each variable. The $\mathrm{T}$ observation values of each parameter are greater than $t_{0.025}$, indicating that the partial regression coefficient of each variable is significant at the 0.05 significance level.

Finally, the regression equation of grouting quantity, grouting pressure, permeability coefficient of sandy medium and water-cement ratio is obtained as follows:

$$
Q=10^{5.211} \cdot X_{1}^{0.745} \cdot X_{2}^{1.956} \cdot X_{3}^{0.475} \cdot t
$$

By comparing the standardized regression coefficients of each variable, it is found that the degree of influence on the grouting quantity is, in turn, grouting pressure, permeability coefficient and water-cement ratio from the largest to the smallest. It can be seen from the spherical diffusion range and its percentage in the total grouting quantity in Table 5 that, with the increase of grouting quantity, the proportion of strip grouting veins presents a decreasing trend. In this test, the proportion of strip slurry pulse was between $40.66 \%$ and $59.13 \%$. The medium permeability coefficient had little influence on the proportion of grouting quantity consumed by spherical diffusion. With the increase of water-cement ratio, the proportion of grouting consumed by spherical diffusion increases gradually.

\section{Engineering Application}

Yuhan tunnel in Jinan, China, is a shallow buried tunnel. The site is mainly composed of backfill, loess, clayey soil and gravelly soil. The groundwater types are Quaternary pore water, gabbro weathering fissure water and karst fissure water. Affected by atmospheric precipitation and surface water seepage of Yuxiu River, temporary stagnant water is formed in local fissures and karst pipelines.

Due to the shallow buried depth of the tunnel, the bearing capacity of the overlying sand layer is insufficient. Surface drilling and grouting are used to reinforce the soft stratum overlying the tunnel to make it have a reliable bearing capacity. In order to retain as much grout as possible in the target reinforcement area, avoid the ineffective diffusion of grout, realize the effective reinforcement of strata and improve the stability of tunnel excavation, the middle rock column need to be grouted. Considering the instability of the sand layer, low pressure permeation grouting is adopted to reinforce the middle wall in the tunnel, as shown in 
Fig. 9. Drilling holes in the ground, using a film bag to seal, and a grout pad at the bottom of the middle wall is set. Under the action of gravity, effective permeation diffusion in the reinforced zone of the middle wall can be realized.

\section{Conclusions}

(1) A theoretical model of point source permeation grouting of Bingham fluid considering gravity is established. In this model, spherical diffusion and strip diffusion reinforce the target area together, the expressions for the radius of spherical grout and the radius of main strip-shaped veins are derived.

(2) The theoretical model is verified by the lowpressure permeation grouting experiment. Based on experimental investigations, the details of grout diffusion are discussed in this paper.

Regression analysis through 30 sets of typical data found that the degree of influence on the grouting quantity from big to small is: grouting pressure, permeability coefficient, and water-cement ratio.

(3) In this test, the proportion of strip grout ranges from $40.66 \%$ to $59.13 \%$, which shows the importance of strip grout in permeation grouting.

(4) In engineering applications, the theoretical model of permeation grouting considering gravity can avoid the loss of grout and strengthen the target area by gravity effectively, which has certain guiding significance for practice.

\section{List of Symbols}

\begin{tabular}{|l|l|}
\hline Symbol & Parameter \\
\hline$r_{l}$ & Radius of axially symmetric fine pipe \\
\hline$m$ & Mass of a section of the fluid column \\
\hline$b$ & Length of a section of the fluid column \\
\hline$r$ & Radius of a section of the fluid column \\
\hline$p$ & Grout pressure \\
\hline$\tau$ & Shear stress of the fluid column \\
\hline$\rho$ & Density of grout \\
\hline$\theta$ & $\begin{array}{l}\text { Angle between gravity and the direction of the } \\
\text { flow }\end{array}$ \\
\hline$\tau_{0}$ & Initial yield shear stress \\
\hline$\eta$ & Viscosity \\
\hline$\gamma$ & Shear rate \\
\hline$r_{0}$ & Cylinder radius \\
\hline$v$ & Fluid velocity \\
\hline$n$ & Porosity of the sandy medium \\
\hline
\end{tabular}

\begin{tabular}{|c|c|}
\hline$\eta_{0}$ & Viscosity of water \\
\hline$\lambda$ & Starting viscosity gradient \\
\hline$v^{\prime}$ & Permeation velocity \\
\hline$Q_{1}$ & Spherical diffusion grout amount ignore gravity \\
\hline$S$ & Surface area of the grout ball \\
\hline$t$ & Grouting time \\
\hline$l$ & Radius of the grout ball \\
\hline$c_{1}$ & Integral constant \\
\hline$l_{0}$ & Radius of the grout ball in the horizontal direction \\
\hline$l_{a}$ & $\begin{array}{l}\text { Radius of the grout ball in the vertical upward } \\
\text { direction }\end{array}$ \\
\hline$l_{b}$ & $\begin{array}{l}\text { Radius of the grout ball in the vertical downward } \\
\text { direction }\end{array}$ \\
\hline$Q_{0}$ & Spherical diffusion grout amount under gravity \\
\hline$v_{2}^{\prime}$ & $\begin{array}{l}\text { Permeation velocity vertically downward in strip- } \\
\text { shape }\end{array}$ \\
\hline$a$ & Radius of grouting pipe \\
\hline$h_{1}$ & $\begin{array}{l}\text { Length of a certain amount grout in the grouting } \\
\text { pipe }\end{array}$ \\
\hline$h_{2}$ & Vertical diffusion distance of the slurry \\
\hline$Q_{a}^{\prime}$ & $\begin{array}{l}\text { Main strip-shape vein grout amount of vertical } \\
\text { permeation }\end{array}$ \\
\hline$f$ & Radius of horizontally permeated grout cylinder \\
\hline$\Delta p$ & Pressure difference \\
\hline$Q_{0}$ & $\begin{array}{l}\text { Amount of grouting consumed by the spherical } \\
\text { diffusion }\end{array}$ \\
\hline$Q_{0}^{\prime}$ & $\begin{array}{l}\text { Amount of grouting consumed by the main strip- } \\
\text { shaped slurry }\end{array}$ \\
\hline$N$ & Number of strip-shaped grout veins \\
\hline$Q_{i}^{\prime}$ & $\begin{array}{l}\text { Each amount of grouting consumed by lateral } \\
\text { strip-shaped veins }\end{array}$ \\
\hline$D$ & $\begin{array}{l}\text { Diameter corresponding to the particle size distri- } \\
\text { bution curve }\end{array}$ \\
\hline$\kappa$ & Permeability coefficient \\
\hline
\end{tabular}

\section{Acknowledgements}

This work was supported by the National Major Research Development Plan of China (grant no. 2016YFC0801604). The model tests were performed at the Geotechnical and Structural Engineering Research Center of Shandong university, and the help is highly appreciated.

\section{Conflict of Interest}

State any potential conflicts of interest here or "The authors declare no conflict of interest". 


\section{References}

1. LI P., ZHANG Q.S., LI S.C., ZHANG X. Time-dependent empirical model for fracture propagation in soil grouting. Tunnelling and Underground Space Technology, 94, 103, 2019.

2. ZHANG J.Q., LI S.C., ZHANG Q.S., ZHANG X., LI P., WANG D.M., WENG X.J. Mud inrush flow mechanisms: a case study in a water-rich fault tunnel. Bulletin of Engineering Geology and the Environment, 78 (8), 6267, 2019.

3. WANG Y., OLGUN C.G., WANG L., MENG B. Risk Assessment of Water Inrush in Karst Tunnels Based on the Ideal Point Method. Polish Journal of Environmental Studies, 28 (2), 901, 2019.

4. STUART L. The Development of Practice in Permeation and Compensation Grouting: A Historical Review (18022002) Part 1 Permeation Grouting. American Society of Civil Engineers, New Orleans, USA, 2003.

5. MARKOU N., DROUDAKIS A. Factors affecting engineering properties of microfine cement grouted sands. Geotechnical and Geological Engineering, 31(4), 1041, 2013.

6. FATTAH M.Y., AL-ANI M.M., AL-LAMY M.T. Studying collapse potential of gypseous soil treated by grouting. Soils and Foundations, 54 (3), 396, 2014.

7. PARK D., OH J. Permeation grouting for remediation of dam cores. Engineering Geology, 233, 63, 2018.

8. BUTRÓN C., GUSTAFSON G., FRANSSON A., FUNEHAG J. Drip sealing of tunnels in hard rock: A new concept for the design and evaluation of permeation grouting. Tunnelling and underground space technology, $25(2), 114,2010$.

9. FUJITA T., SHINKAI F., NOBUTO J. Fundamental study on a grout penetration model for a HLW repository. Journal of Energy and Power Engineering, 6 (8), 1191, 2012.

10. HAN W. Grouting Mechanism Based on Filtration in Porous Media with Cement Grout and Its Engineering. Shandong University, Jinan, China, 2014 [In Chinese].

11. HUANG H., RONG Y. Analysis of driving-water permeation grouting of saturated sand seam. Rock and Soil Mechanics, 30 (7), 2016, 2009 [In Chinese].
12. SUN B.T., LING X.Z., LING C., ZHU G.R. Numerical simulation for diffusion and pressure distribution of permeation grouting. Journal of Hydraulic Engineering, 38 (11), 1402, 2007.

13. XIAO F., ZHAO Z., CHEN H. A simplified model for predicting grout flow in fracture channels. Tunnelling and Underground Space Technology 70, 11, 2017.

14. ZHANG Q.S, ZHANG L.Z., LIU R.T., LI S.C., ZHANG Q.Q. Grouting mechanism of quick setting slurry in rock fissure with consideration of viscosity variation with space. Tunnelling and Underground Space Technology 70, 262,2017

15. CELIK F. The observation of permeation grouting method as soil improvement technique with different grout flow models. Geomechanics and Engineering, 17 (4), 367, 2019.

16. SAADA Z., CANOU J., DORMIEUX L., DUPLA J.C., MAGHOUS S. Modelling of cement suspension flow in granular porous media. International journal for numerical and analytical methods in geomechanics, 29 (7), 691, 2005.

17. SAADA Z., CANOU J., DORMIEUX L., DUPLA J.C. Evaluation of elementary filtration properties of a cement grout injected in a sand. Canadian Geotechnical Journal, 43 (12), 1273, 2006.

18. MAGHOUS S., SAADA Z., DORMIEUX L., CANOU J., DUPLA J.C. A model for in sit grouting with account for particle filtration. Computers and Geotechnics, 34 (3), 164, 2007.

19. GUSTAFSON G., CLAESSON J., FRANSSON A. Steering parametersfor rock grouting. Journal of Applied Mathematics, 2013 (1), 01, 2013.

20. DAYAKAR P., RAMAN K.V., RAJU K.V.B. Study on permeation grouting using cement grout in sandy soil. IOSR Journal of Mechanical and Civil Engineering, 4 (4), 05, 2012.

21. YANG Z., HOU K., GUO T., MA Q. Study on penetration grouting mechanism based on Bingham fluid of timedependent behavior. Journal of Sichuan University (Engineering Science Edition), 43, 67, 2011 [In Chinese]. 